\title{
Oxidative Stress Levels in Orthodontic Patients and Efficacy of Antioxidant Supplements in Combating Its Effects- A Randomized Clinical Study
}

\author{
Dr Sheetal Yamyar,' Dr Suchita Daokar² \\ Senior Lecturer, ${ }^{2}$ Professor, \\ Dept of Orthodontics, CSMSS Dental College \& Hospital, Aurangabad, Maharashtra, India \\ Correspondence: Dr Sheetal Yamyar; Email: sheetal.yamyar@gmail.com
}

\section{ABSTRACT}

Introduction: Orthodontic appliances are considered to be biocompatible although adverse effects attributed to release of nickel ion which are free radicals in oral cavity. These free radical produce damages both in cellular and extracellular components phospholipid membrane, proteins, mitochondrial and nuclear DNA leading to Oxidative stress which is normally counter balanced by the action antioxidant mechanisms. However in higher concentrations of free radicals resulting in cellular death and apoptosis Orthodontic appliances such as brackets, wire, resins has considered as potential allergen leading to release of free radicals. The study was conducted to determine and compare the role of oxidative stress and role of antioxidants in saliva of patients undergoing fixed orthodontic appliances therapy at different time intervals.

Materials \& Method: A double-blinded, parallel, randomized clinical study was designed consisting of 40 healthy participants, aged 15-30yrs. The samples were divided into two groups Group A without antioxidants supplements and Group B with antioxidants supplements. Salivary MDA levels and gingival health index was recorded at different time intervals from each group. Salivary Lipid peroxidation (Malondialdehyde) level was estimated using Thiobarbituric acid (TBA) method and gingival status was investigated using Silness \& Loe gingival index. Intragroup and intergroup comparison was statistically analyzed using student's paired T test.

Result: Increased salivary MDA levels and mild to moderate amount of gingivitis is seen in both groups. This is more pronounced after 24 hours of appliance placement. Improvement in salivary MDA levels and gingival health status is observed during the course of treatment, In Group B the salivary MDA levels and gingival health index score reached below their pretreatment values. However even after a span of 3 months the levels remained higher to their base values in Group A.

Conclusion: Improvement in salivary MDA levels and gingival health status is observed following antioxidant therapy during course of treatment, indicating combating nature of antioxidant supplements in orthodontic patients.

Keywords: Antioxidants, Free radicals, Lipid peroxidase, MDA, Oxidative stress.

\section{INTRODUCTION}

Recent decades have seen great interest in the biocompatibility aspects of biomaterials. ${ }^{1,2}$ In normal physiology there is a dynamic equilibrium between ROS activity and antioxidant defence capacity. Normal cellular defence mechanisms destroy most of these ROS and free radicals. ${ }^{3}$ Likewise, any damage to cells is constantly repaired. ${ }^{4}$

However appliances and additional devices used during orthodontic treatment are exposed to different factors, such as temperature, $\mathrm{pH}$, mechanical stress (corrosion), and micro flora (bio-corrosion) in oral cavity. ${ }^{2}$ All these factors lead to release of toxic metal ions from alloy. Degradation products released from brackets and/or arch wires undergoes redox cycles and thus indirectly generates free radicals leading to oxidative stress. ${ }^{5}$
Free radicals are highly reactive and have very short span of life. Considering this, the damage produced by a free radical ROS damages all components of the cell, including proteins, lipids, and DNA. ${ }^{6}$ However, the most important cellular targets of oxidative stress are the phospholipid membranes. ${ }^{7}$ When it reacts with lipids the by-product of the reaction is lipid peroxidation. ${ }^{8}$ It is the process in which free radicals "steal" electrons from the lipids present in cell membranes, resulting in cell damage. ' Lipid peroxides attack on polyunsaturated fatty acids one of the by-product of this reaction is MDA. ${ }^{10}$

Saliva, an important physiologic fluid, containing a highly complex mixture of substances, is rapidly gaining popularity as a diagnostic tool. ${ }^{11}$ It carries important relevant information in the form of biomarkers and act as a mirror of oral and systemic health. ${ }^{12}$ Saliva can be used as a medium to analyse the oxidative stress levels in terms of MDA. ${ }^{13}$ 
Antioxidants neutralize free radicals. They may be classified as enzymatic and non enzymatic. They act as scavengers, helping to prevent cell and tissue damage. ${ }^{14}$ The most well research non enzymatic antioxidant includes lipid soluble vitamin $\mathrm{E}$ and water soluble vitamin $\mathrm{C}$ and vitamin $\mathrm{A} .{ }^{15}$

Recently, it has been claimed that the imbalances in the levels of free radicals and antioxidants in saliva may play an important role in the onset of periodontal diseases. ${ }^{15}$

However literature lack studies whether dietary supplements of antioxidants can combat with the oxidative stress induced by orthodontic appliances and improve the gingival health status of orthodontic patients. Hence this study was undertaken to study the effect of dietary supplements on salivary MDA level and gingival health status of orthodontic patients.

\section{MATERIALS AND METHOD}

\section{Study Design}

The study was designed to be double blinded and randomized consisting of forty healthy patients aged 18$30 y$ rs who were supposed to undergo fixed orthodontic treatment. The patients were randomly selected from the outpatient department of orthodontics using simple random sampling techniques. The CONSORT statement was used as a guide for this study. ${ }^{16}$

\section{Ethical Approval and Informed Consent}

Ethical approval of this prospective clinical study was obtained from the local ethics committee of our institute and University vide letter no MUHS /PG/E$2 / 1190 / 14$. Written consent was retrieved before commencement of the study.

\section{Sample Size Calculation}

The sample size was determined from a previous study. ${ }^{17}$ Our standard difference $=0.6$ and power $=80$; 20 was the number of volunteers needed per group.

\section{Clinical Study Protocol}

Inclusion criteria: No history of systemic disease, not undergoing any prior medication, not suffering from xerostomia.

Exclusion criteria; Patients suffering from systemic diseases \&/or xerostomia and those reporting the use of medications.

\section{Randomization}

Patients were allocated to the control group or an experimental group with an allocation ratio of $1: 1$ using a simple randomized controlled trial method with coin toss method.

\section{Clinical Procedure}

Group 1- Controlled group [without antioxidants] consisted of twenty patients. Group 2- Experimental group [with antioxidants] consisted of twenty patients.

Subjects belonging to both the groups were treated with fixed orthodontic mechanotherapy. Appliance of choice was SS MBT 0.022" prescription with 0.014" NiTi wire for initial levelling and aligning. Subjects belonging to Group 2 were prescribed daily dose of one tablet OXITARD [Himalaya Drug Company] (Vitamin A, vitamin $E$ and vitamin C), whereas subjects from Group 1 were given daily dose of 1 tablet placebo for three months.

Oxitard is a non-enzymatic, secondary, dietary supplement drug having high ORAC (Oxygen Radical Absorbance Capacity) value. Higher the ORAC value of the drug, higher is its antioxidant potential.

Saliva collection method: Whole saliva was collected from each subject. Saliva collection was collected from each participant at four different occasions, i.e one day prior to appliance placement, 24hrs, 7 days and 3 months after complete appliance placement. The coding of the saliva samples was not disclosed to the laboratory personnel to minimize experimental bias.

\section{Outcomes}

The saliva was centrifuged at $3000 \mathrm{rpm}$ for $15 \mathrm{~min}$ in centrifuging machine. Salivary MDA levels using Satoh TBA method18 (1978) and gingival health status using Loe and Silness gingival index18 (1963) (chart no 1) was assessed for all the patients at four different time intervals.

\begin{tabular}{|c|l|}
\hline SCORE & \multicolumn{1}{|c|}{ CRITERIA } \\
\hline 0 & NORMAL GINGIVA \\
\hline 1 & $\begin{array}{l}\text { MILD INFLAMMATION, SLIGHT CHANGE IN COLOUR, } \\
\text { SLIGHT EDEMA, NO BLEEDING ON PROBING }\end{array}$ \\
\hline 2 & $\begin{array}{l}\text { MODERATE INFLAMMATION: MODERATE GLAZING, } \\
\text { REDNESS, EDEMA, HYPERTROPHY AND BLEEDNG ON } \\
\text { PROBING }\end{array}$ \\
\hline 3 & $\begin{array}{l}\text { SEVERE INFLAMMATION: MARKED REDNESS, EDEMA, } \\
\text { ULCERATION, TENDENCY TO SPONTANEOUS BLEEDING }\end{array}$ \\
\hline & Chart No.1. Gingival Health Index ${ }^{17}$ \\
\hline
\end{tabular}




\section{Error of the Method}

All the measurements were done by single examiner. The intra examiner reliability for data readings was assessed using Kappa statistics which was found to be $94 \%$.

\section{RESULT}

Intragroup and intergroup comparison of salivary MDA levels and gingival health index was statistically analysed using standard paired t test.

\section{Comparison of Mean Level}

In Group A, MDA levels were found to be 10.348 , $0.089),(1.166,0.293),(0.908,0.206),(0.759,0.118)$ at time intervals. The values were found to be statistically significant (0.000) (Table no. 1)

In Group B, MDA levels were found to be 10.348 , 0.087), (1.067, 0.31), (0.773, 0.292), (0.289, 0.081) at time intervals. The values were found to be statistically significant (0.000) at all the time intervals after appliance placement. (Table no. 2)

\section{Intergroup comparison of salivary MDA level:}

MDA levels when compared among the groups using Student T test showed statistically insignificant difference at time intervals $(P=0.203,0.304,0.098$ ) respectively, however after 3 months there was significant difference MDA levels among two groups. $(P=0.000)$ (Table no. 3.)

\section{Gingival health status}

aln Group A, the mean and standard deviation of gingival health index score were found to be (1.11, 0.297), (2.44, 0.471), (2.56, 0.153), (2.15, 0.146) at time intervals. When compared using student $T$ test, the values were found to be statistically significant (0.000) at all the time intervals after appliance placement. (Table no. 4)

In Group B, the mean and standard deviation of gingival health index score were found to be $(1.15$, $0.375),(2.16,0.264),(1.14,0.356),(0.54,0.335)$ at time intervals. The values were found to be statistically significant (0.000) (Table no. 5).

Table 1: Comparison of Mean MDA Level Controlled Group (Group A)

\begin{tabular}{|l|c|c|c|c|c|}
\hline \multicolumn{1}{|c|}{ TIME } & MEAN & SD & T VALUE & P VALUE & RESULT \\
\hline PRE TREATMENT & 0.348 & 0.089 & & & \\
\hline AFTER 24HRS & 1.166 & 0.293 & 12.598 & 0.000 & SIGNIFICANT \\
\hline AFTER SEVEN DAYS & 0.908 & 0.206 & 12.049 & 0.000 & SIGNIFICANT \\
\hline AT 3 MONTHS & 0.759 & 0.118 & 13.738 & 0.000 & SIGNIFICANT \\
\hline
\end{tabular}

Table 2: Comparison of Mean MDA Level Exprimental Group (Group B)

\begin{tabular}{|l|c|c|c|c|c|}
\hline \multicolumn{1}{|c|}{ TIME } & MEAN & SD & T VALUE & P VALUE & RESULT \\
\hline PRE TREATMENT & 0.384 & 0.087 & & & \\
\hline AFTER 24HRS & 1.067 & 0.31 & 9.48 & 0.000 & SIGNIFICANT \\
\hline AFTER SEVEN DAYS & 0.773 & 0.292 & 5.69 & 0.000 & SIGNIFICANT \\
\hline AT 3 MONTHS & 0.289 & 0.808 & 3.57 & 0.001 & SIGNIFICANT \\
\hline
\end{tabular}

Table 3: Inter Group comparison of MDA Level at different time interval

\begin{tabular}{|c|c|c|c|c|c|}
\hline TIME & INTER GROUPS & SD & T value & $P$ value & RESULTS \\
\hline \multirow{2}{*}{ PRETREATMENT } & GROUP A & 0.089 & & \multirow{2}{*}{0.203} & \multirow{2}{*}{ NOT SIGNIF-ICANT } \\
\hline & GROUP B & 0.089 & 1.294 & & \\
\hline \multirow{2}{*}{ AFTER 24 HRS } & GROUP A & 0.293 & & \multirow{2}{*}{0.304} & \multirow{2}{*}{ NOT SIGNIF-ICANT } \\
\hline & GROUP B & 0.31 & 1.043 & & \\
\hline \multirow{2}{*}{ AFTER 7 Days } & GROUP A & 0.206 & 1.698 & \multirow{2}{*}{0.098} & \multirow{2}{*}{ NOT SIGNIF-ICANT } \\
\hline & GROUP B & 0.292 & & & \\
\hline \multirow{2}{*}{ AFTER MONTHS } & GROUP A & 0.118 & 14.631 & \multirow{2}{*}{0.000} & \multirow{2}{*}{ NOT SIGNIF-ICANT } \\
\hline & GROUP B & 0.808 & & & \\
\hline
\end{tabular}

Table 4: Comparison of Gingival Health Status - without Antioxidant Group (Group A )

\begin{tabular}{|l|c|c|c|c|c|}
\hline \multicolumn{1}{|c|}{ TIME } & MEAN & SD & T VALUE & P VALUE & RESULT \\
\hline PRE TREATMENT & 1.11 & 0.297 & & & \\
\hline AFTER 24HRS & 2.44 & 0.471 & 10.46 & 0.000 & SIGNIFICANT \\
\hline AFTER SEVEN DAYS & 2.56 & 0.153 & 18.89 & 0.000 & SIGNIFICANT \\
\hline AT 3 MONTHS & 2.15 & 0.146 & 13.67 & 0.000 & SIGNIFICANT \\
\hline
\end{tabular}


Table 5: Comparison of Gingival Health Status - with Antioxidant Group (Group B )

\begin{tabular}{|l|c|c|c|c|c|}
\hline \multicolumn{1}{|c|}{ TIME } & MEAN & SD & T VALUE & P VALUE & RESULT \\
\hline PRE TREATMENT & 1.15 & 0.375 & & & \\
\hline AFTER 24HRS & 2.16 & 0.264 & 9.9 & 0.000 & SIGNIFICANT \\
\hline AFTER SEVEN DAYS & 1.14 & 0.356 & 2.23 & 0.034 & SIGNIFICANT \\
\hline AT 3 MONTHS & 0.54 & 0.335 & 5.38 & 0.000 & SIGNIFICANT \\
\hline
\end{tabular}

Table 3: Inter Group Comparison of Gingival Health Status at different time interval

\begin{tabular}{|c|c|c|c|c|c|}
\hline TIME & INTER GROUPS & SD & T value & $P$ value & RESULTS \\
\hline \multirow{2}{*}{ PRETREATMENT } & GROUP A & 0.297 & & \multirow{2}{*}{0.763} & \multirow{2}{*}{ NOT SIGNIF-ICANT } \\
\hline & GROUP B & 0.375 & 0.317 & & \\
\hline \multirow{2}{*}{ AFTER 24 HRS } & GROUP A & 0.471 & & \multirow{2}{*}{0.215} & \multirow{2}{*}{ NOT SIGNIF-ICANT } \\
\hline & GROUP B & 0.264 & 2.11 & & \\
\hline \multirow{2}{*}{ AFTER 7 Days } & GROUP A & 0.293 & 13.09 & \multirow{2}{*}{0.508} & \multirow{2}{*}{ NOT SIGNIF-ICANT } \\
\hline & GROUP B & 0.356 & & & \\
\hline \multirow{2}{*}{ AFTER MONTHS } & GROUP A & 0.145 & 19.31 & \multirow{2}{*}{0.000} & \multirow{2}{*}{ SIGNIF-ICANT } \\
\hline & GROUP B & 0.334 & & & \\
\hline
\end{tabular}

\begin{tabular}{|c|c|c|}
\hline & Assessed for eligibity $(n=67)$ & \\
\hline & & $\begin{array}{c}\text { Excluded }(n=27) \\
\text { Not meeting the inclusion criteria }(n=21) \\
\text { Declined to participate }(n=6)\end{array}$ \\
\hline & Randomized $(n=40)$ & \\
\hline & Allocation & \\
\hline $\begin{array}{l}\text { Allocated control group ( } n=20) \\
\text { Received allocated intervention }\end{array}$ & & $\begin{array}{l}\text { Allocated experimental group }(n=20) \\
\text { Received allocated intervention }\end{array}$ \\
\hline & Follow up & \\
\hline $\begin{array}{l}\text { Loss to follow up }(n=0) \\
\text { Discontinued intervention }(n=0)\end{array}$ & & $\begin{array}{l}\text { Loss to follow up }(n=0) \\
\text { Discontinued intervention }(n=0)\end{array}$ \\
\hline & Analysis & \\
\hline $\begin{array}{c}\text { Analysed }(n=20) \\
\text { Excluded from analysis }(n=0)\end{array}$ & & $\begin{array}{c}\text { Analysed }(n=20) \\
\text { Excluded from analysis }(n=0)\end{array}$ \\
\hline
\end{tabular}

\section{Chart No. 2. CONSORT flow diagram}

\section{Intergroup comparison of gingival health index score}

Gingival health index score when compared among the groups showed statistically insignificant difference at time intervals. ( $P=0.753,0.215,0.508)$ respectively, however after 3 months there was significant difference in MDA levels among two groups. $(P=0.000)$ (Table no. 6).

\section{DISCUSSION}

Over the past few years, strong evidence has emerged to implicate oxidative stress in pathogenesis of dental disease. At low concentration, they stimulate the growth of fibroblasts and epithelial cells in culture, but at higher concentrations it may result in tissue injury. ${ }^{19}$

An Orthodontic appliance remain in mouth for 2 years or more where saliva is the connecting media, may produce electro galvanic currents that produce a discharge of ions. ${ }^{20}$

The harmful effects of freeradicals are counterbalanced by an antioxidant mechanism. ${ }^{21}$ A change in this 
balance in favour of free radicals deteriorates the oxidative balance and produces oxidative tissue damage associated with oxidative stress. ${ }^{21,22}$

Saliva reflects general health status of the human organism and is easy to collect, it can be used as a non-invasive diagnostic tool. ${ }^{23}$

This study was undertaken to determine whether oxidative stress are induced by orthodontic appliance, role of antioxidants on oxidative stress and also its effect on gingival health.

In present study MDA levels were significantly increased after $24 \mathrm{hrs}$ in comparison of pre-treatment values in both groups. There was constant decline in the MDA levels after seven days to three months but yet not reaching to the base values. This can be attributed to the fact that metal ions release from appliances are higher in first $24 \mathrm{hrs}$. The results were same with findings reported by Nilforoushan et $\mathrm{al}^{24}$ and Maja khuta et $\mathrm{al}^{25}$ The study was also in accordance to D'Attitillo et al ${ }^{26}$ and Oltleanu et $\mathrm{al}^{27}$ who stated that radical ions were higher in early stages of treatment.

In antioxidant group the results were also seen to exceed from base line to seven days and were statistically significant, however after three months, MDA levels were lower than the baseline values and were significant. The antioxidants prescribed to the patients combated with the free radicals formed due to metal ions. These findings were in correlation of Rai et $\mathrm{al}^{28}$ and Das et $\mathrm{al}^{29}$ who studied the effects of antioxidants in diseases.

The MDA level among the two groups showed insignificant difference. However after 3 months there was significant difference in MDA levels among the two groups. $(P=0.000)$. These findings indicate that oxidative stress are built up at 3 months was combated by antioxidants.

The second part of study was to determine the effects of oxidative stress on gingival health and role of antioxidants during the treatment. Oral hygiene was maintained yet gingival inflammation was seen in both the groups. As explained earlier releases of metal ions were higher at initial stages of appliance placement. This increase in oxidative stress levels in the initial period may be the reason of gingival tissues inflammation as suggested by Grimsdottir et al30 and Buljan et al. ${ }^{31}$ The results of our study were in accordance to the findings of Ajith Pillai ${ }^{32}$ and Faccioni et $\mathrm{al}^{33}$ who reported in their study that metal release of minimum concentration of $1.18 \mathrm{~g}$ could damage the gingival fibroblast at 72hrs exposure. At three months in antioxidant group, the patient's Gl score dropped from base values. The results of our study are seen in collaboration to the results of study conducted by Benjamin. ${ }^{17}$ They reported reduction in BOP, $G$ in the patients treated with local applicant of antioxidant -essential oil gel. The highly significant difference between the two groups can be explained by the fact that antioxidant supplements prescribed had its effect on combating with oxidative stresses generated by the orthodontic appliance.

The results of our study are in contrast with the results of Elcin Esenlick ${ }^{34}$ studied role of (vitamin E) on lipid peroxidation levels in GCF of 50 orthodontic patients may be due to the difference in medication and protocol followed. In ourstudy antioxidants supplements prescribed for 3 months included vitamin A, vitamin C and vitamin $E$, whereas in Esenlick study only vitamin E was prescribed for a 1 month. Micronutrients such as beta-carotene and vitamins A, C and E can be depleted during inflammation. ${ }^{6}$ As mitochondria, release ROS in the cell. In a study in Schectman ${ }^{35}$ et al suggested that vitamin $C$ enters the mitochondria and protects against oxidative injury. These vitamins maintens structural and functional integrity of epithelial tissues and physiological or metabolic parameters of periodontal health. ${ }^{35}$ Gingival health status is observed during the course of treatment, but do not reach its pre-treatment values. This may be due to oxidative stress induced by the leached metal ions from the appliance. Prescription of antioxidant has shown to deal with this problem in a time span of 3 months. However in this study, no changes in the archwire or ligatures were done throughout the study.

\section{CONCLUSION}

Our study concludes that even after thorough oral hygiene maintenance in orthodontic patients, increased salivary MDA levels and mild to moderate amount of gingivitis is seen in both groups. Improvement in salivary MDA levels and gingival health status is observed during the course of treatment, however even after a span of 3 months the levels remained higher to their base values due leaching of ions. where as in Antioxidant group the salivary MDA levels after 3 months were below the pretreatment values. Prescription of antioxidant tab has shown to deal in a time span of 3 months Hence further studies are recommended to study long term effect of the fixed appliance on lipid peroxidation and whether antioxidant supplements should be continued throughout the treatment to combat with oxidative stress. 


\section{REFERENCES}

1. Eliades T, Athanasiou AE. In vivo aging of orthodontic alloys: implications for corrosion potential, nickel release, and biocompatibility. Angle Orthod. 2002; 72:222-237.

2. Marcin Mikulewicz, Katarzyna Chojnacka, Paulina Wołowiec. Release of metal ions from fixed orthodontic appliance: An in vitro study in continuous flow system. Angle Orthod. 2014; 84:140-148

3. Ames BN, Shigenaga MK, Hagen TM. Oxidants, antioxidants, and the degenerative diseases of aging. Proc Natl Acad Sci USA 1993: 90(17):7915-7922

4. Schafer FQ, Buettner GR. Redox environment of the cell as viewed through the redox state of the glutathione disulfide/glutathione couple. Free Radic Biol Med 2001; 30(11):1191-1212

5. Halliwell B. Free radicals, reactive oxygen species and human disease: a critical evaluation with special reference to atherosclerosis. British journal of experimental pathology. 1989; 70(6):737-757.

6. Halliwell B. Free radicals and antioxidants: updating a personal view. Nutr Rev 2012; 70(5):257-265

7. Seet RC, Lee CY, Loke WM, et al. Biomarkers of oxidative damage in cigarette smokers: which biomarkers might reflect acute versus chronic oxidative stress? Free Radic Biol Med 2011; 50(12):1787-179311

8. Valko M, Morris H, Cronin MT. Metals, toxicity and oxidative stress. Curr Med Chem 2005; 12(10):1161-1208.

9. Halliwell B. Reactive oxygen species in living systems: source, biochemistry, and role in human disease. Am J Med 1991; 91 (3C):14S-22S. .

10. Mandel ID. The diagnostic uses of saliva. J Oral Pathol Med 1990; 19:119-25

11. Sies H. Oxidative Stress: Oxidants and Antioxidants. Experimental Physiology 1997; 82:291-295.

12. Draper HH, Haley M. Malondialdehyde determination as index of lipid peroxidation. Methods Enzymol 1990; 186:421-31.

13. Fratelli M, Goodwin LO, Orom UA, et al. Gene expression profiling reveals a signaling role of glutathione in redox regulation. Proc Natl Acad Sci U S A 2005; 102(39):13998-14003

14. Devasagayam T, Tilak JC, Boloor KK, Sane Ketaki S, Ghaskadbi Saroj S, Lele RD. Free Radicals and Antioxidants in Human Health: Current Status and Future Prospects. J Assoc Physicians India. 2004; 52:794-804.

15. Panjamurthy K, Manoharan S, Ramachandran CR. Lipid peroxidation and antioxidant status in patients with periodontitis. Cell Mol Biol Lett 2005; 10: 255-64.

16. CONSORT. http://www.consort-statement.org/consortstatement.

17. Benjamin J. Martin, Phillip M. Campbell, Terry D. Rees, and Peter H. Buschang. A randomized controlled trial evaluating antioxidant-essential oil gel as a treatment for gingivitis in orthodontic patients. The Angle Orthodontist 2016;86: 407-412

18. Satoh, K. Serum lipid peroxide in cerebrovascular disorder determined by a new colorimetric method. Clin. Chem. Acta 1978; 90:37- 43.

19. Loe H. and Silness, J. Periodontal disease in pregnancy. I. Prevalence and severity, Acta Odont Scand 1963; 21:533-551.

20. Abdul S Aziz, Madhav G Kalekar, Tabita Benjamin. Effect of Nonsurgical Periodontal Therapy on Some Oxidative Stress Markers in Patients with Chronic Periodontitis: A Biochemical Study. World Journal of Dentistry 2013; 4(1):17-23.

21. Janson GR,Dainesi EA,Consolaro A. Nickel hypersensitivity reaction before, during and after orthodontic therapy. Am J Orthod Dentofac orthop 1998; 113(6):655-60.

22. Dayan AD, Paine AJ. Mechanisms of chromium toxicity, carcinogenicity and allergenicity: review of the literature from 1985 to 2000 . Hum Exp Toxicol. 2001; 20(9):439-51.

23. C. F. Canakci, Y. Cicek, A. Yildirim, U. Sezer, V. Canakci. "Increased levels of 8-hydroxydeoxyguanosine and malondialdehyde and its relationship with antioxidant enzymes in saliva of periodontitis patients." European Journal of Dentistry, 2009; 3:100-106.

24. D. Nilforoushan and M. F. Manolson, "Expression of nitric oxide synthases in orthodontic tooth movement," Angle Orthod 2009; 79:502-508.

25. Maja Kuhta, Dubravko Pavlin, Martina Slaj, Suzana Varga, Marina Lapter-Varga, Mladen Slaj. Type of Archwire and Level of Acidity: Effects on the Release of Metal Ions from Orthodontic Appliances. Angle Orthod 2009; 79:102-110.

26. M. D'Attillio, F. Di Maio, C. D'Arcangela. "Gingival endothelial and inducible nitric oxide synthase levels during orthodontic treatment: a cross-sectional study." Angle Orthod 2004; 74:851-858

27. Olteanu, C. Variations of some saliva markers of the oxidative stress in patients with orthodontic appliances." Academic Journal of Physiology 2009; 19:20.

28. Rai, Balwant. "Possible action mechanism for curcumin in pre-cancerous lesions based on serum and salivary markers of oxidative stress." Journal of oral science 2010; 52 : 251-256.

29. Das, Kusal K. "A Comprehensive Review on Nickel (II) and Chromium VI Toxicities-Possible Antioxidant (Allium Sativum Linn) Defenses." Al Ameen J Med Sci 2009; 22: 43-50.

30. Grimsdottir MR, Gjerdet NR, Hensten-Pettersen A. Composition and in vitro corrosion of orthodontic appliances. Am J Orthod Dentofac Orthop 1992; 101:525-32.

31. Buljan, Zorana Ivankovic. "In vitro oxidative stress induced by conventional and self-ligating brackets." Angle Orthod 201 1; $82: 340-345$.

32. Pillai, Ajith Rajasekharan, et al. "Cytotoxic effects of the nickel release from the stainless steel brackets: An in vitro study." Journal of pharmacy \& bioallied sciences 2013 Jun; 5(Suppl 1): S1-S4

33. Faccioni F, Franceschetti P, Cerpelloni M., et al. "In vivo study on metal release from fixed orthodontic appliances and DNA damage in oral mucosa cells" Am J Orthod Dentofac Orthop 2003;124:687-94.

34. Esenlik E, Naziroğlu M, Açikalin C, Övey IS. Vitamin E supplementation modulates gingival crevicular fluid lipid peroxidation and antioxidant levels in patients with orthodontic tooth movement. Cell Biochem Funct. $2012 \mathrm{Jul} ; 30$ (5):376-81

35. Schectman G, Byrd JC, Gruchow HW. The influence of smoking on vitamin C status in adults. Am J Public Health 1989; 79(2):158-162 